\section{AVALIAÇÃO DE TRABALHO CIENTÍFICO}

Considero interessante e oportuno o artigo intitulado: "Critérios quantitativos para analisar o valor da publicação de artigos cientíícos", de autoria do eminente cirurgião e pesquisador da Faculdade de Medicina da UFMG, Andy Petroianu (Rev Assoc Med Bras 2003; 49(2): 173-6), o que me motivou fazer alguns comentários.

Atualmente, a avaliação de títulos e trabalhos constantes em Curriculum Vitae e/ ou Memorial Descritivo para concursos acadêmicos e outros é dotada de muita subjetividade, apadrinhamento e, muitas vezes, de julgamentos político-ideológicos. É o que mostra o cotidiano das universidades públicas brasileiras. Vejam uma afirmação rotineira: "esse concurso foi/é ou será um jogo de cartas marcadas". Vale relembrar o dito: "aprovas o meu amigo e assistente predileto hoje, que eu aprovarei o seu amanhã". Esse artigo fundamenta-se na ética e na razão; portanto, pode ser um ponto de referência valorosa para o exercício de um bom julgamento. Julgar com imparcialidade é difícil. Apenas Deus é imparcial. O evangelho, segundo São Mateus, nos ensinou a prudência: "Não julgueis para não serdes julgados. Pois com o julgamento com que julgais sereis julgados, e com a medida com que medis sereis medidos".

Faz-se necessária a publicação dos critérios ou normas prévias para avaliação de títulos e trabalhos em concursos docentes. Sob o manto de editais que mencionam que "a banca examinadora é soberana", se esconde o pré-julgamento, o acerto de contas, a vingança pessoal, a injustiça planejada e posteriormente executada. Os préSocráticos afirmaram que "é mais vergonhoso para quem pratica a injustiça do que para quem sofre".

$\mathrm{O}$ artigo publicado do ilustre livre-docente tenta produzir uma eqüidade de justiça e uma minimização dos juízos de valores, obviamente evitando as interferências subjetivas.

Por tudo isso, e algo mais, eu assino em baixo.

Paulo César Alves Carneiro Rio de Janeiro - RJ

\section{Resposta do autor}

Agradecemos a gentileza de nos conceder a oportunidade para responder aos comentários do Prof. Paulo César Alves Carneiro com respeito a nosso artigo "Critérios quantitativos para analisar o valor da publicação de artigos científicos".

Tendo em vista que o prof. Carneiro não nos fez indagação alguma, resta-nos apenas agradecer a deferência feita por ele ao nosso trabalho.

Continuamos à disposição de V. Sa. para o que pudermos ser úteis e apresentamos os nossos votos de muita saúde.

Atenciosamente,

Andy Petroianu Belo Horizonte - MG

\section{FUNGOS ANEMÓFILOS}

$\mathrm{O}$ artigo de Mezzari et al., em Porto Alegre' é uma importante contribuição ao conhecimento de aeroalérgenos, e deve estimular pesquisa semelhante em outras regiões de nosso país. Um dos objetivos do estudo foi caracterizar a concentração de esporos de fungos anemófilos.

O coletor de esporos usado pelos autores permitia a quantificação dos elementos e, pela descrição dos métodos, o resultado final seria expresso em número de esporos por $\mathrm{m}^{3}$ de ar em 24 horas. Seria muito útil que esses resultados numéricos fossem apresentados, pois demonstrariam a intensidade da dispersão aérea dos esporos. Esta, sim, pode indicar, além da presença dos esporos, o grau de exposição dos indivíduos aos fungos do ar e sua relevância à sensibilização e desencadeamento de sintomas nos alérgicos.

Fatores ambientais como temperatura, umidade relativa do ar, índice de precipitação pluviométrica e velocidade e direção dos ventos influenciam diretamente a presença de fungos e esporos².

Em algumas áreas, "epidemias de asma", com o aumento no número de hospitalizações por crises agudas de asma, coincidem com picos nas contagens de esporos de fungos ${ }^{3}$.

Outro aspecto que os autores deveriam ter abordado era a distribuição das espécies e respectivas contagens durante as 52 semanas, para infomar se ocorreram picos no período que pudessem ser relacionados às condições atmosféricas referidas. Sabe-se que alguns fungos do ambiente externo desenvolvem-se melhor quanto maior a umidade e outros liberam mais esporos no ambiente menos úmido e com vento 4 .

No hemisfério Norte, em geral, ocorrem picos nas contagens de esporos no final do verão e início do outono. Por exemplo, durante o verão na cidade de Kansas, EUA, as contagens diárias médias, muitas vezes excedem 30.000 esporos por $\mathrm{m}^{3}$ de $a r^{5}$.

O National Allergy Bureau da Academia Americana de Alergia, Asma e Imunologia, que consiste em uma rede de 51 estações certificadas para contagem de pólens e esporos nos EUA, considera baixa a contagem entre 0 e 6.500 esporos $/ \mathrm{m}^{3}$, moderadas as contagens entre 6.501 e 13.000 esporos $/ \mathrm{m}^{3}$ e altas as contagens superiores a $13.000 / \mathrm{m}^{3}$.

Portanto, seria interessante se os autores pudessem comparar as contagens em Porto Alegre com os padrões existentes. A propósito, seria um desafio para pesquisadores brasileiros formar uma rede e estabelecer padrões próprios que viessem a auxiliar o clínico no diagnóstico das alergias respiratórias.

\section{Nelson Rosário filho} Curitiba - PR

\section{Referências}

1. Mezzari A, Perin C, Santos Junior SA, Bernd LAG, Di Gesu G. Os fungos anemófilos e sensibilização em indivíduos atópicos em Porto Alegre, RS. Rev Assoc Med Bras 2003; 49:270-3.

2. Weber RC. Meteorologic variables in aerobiology. Immunol Allergy Clin North Am 2003;23:4II-22.

3. Dziadzio L, Bush RK. Assessment and control of fungal allergens. Curr Allergy Asthma Rep 200 I; : :455-60.

4. Brooks GD, Bush RK. Allergens and other factors important in atopic disease. In: Grammer LC e Greenberger PA, editors. Patterson's. Allergic Diseases $6^{\circ}$ Edição, Philadelphia, Lippincott Williams \& Wilkins, 2002, p. 81.

5. Portnoy J, Barnes C. Clinical relevance of spore and pollen counts. Immunol Allergy Clin N Am 2003;23:389-4I0. 


\section{Resposta dos autores}

Consideramos muito interessante a carta do Dr. Nelson Rosário Filho com referências à pesquisa de fungos anemófilos realizada em Porto Alegre porque nos permite salientar certos aspectos do trabalho que talvez não tenham sido suficientemente enfatizados.

Com o intuito de difundir entre os alergologistas o conhecimento e suscitar novas pesquisas, os dados que vínhamos levantando foram apresentados em 2000 e 2002, em Congressos da Sociedade Brasileira de Alegria e Imunopatologia, da qual o Dr. Rosário é o presidente eleito, e, em eventos internacionais, como o Congresso da European Academy of Allergollogy and Clinical Immunology, em Berlim, 200l I-5. $^{2}$.

A identificação e a concentração de esporos no ar de Porto Alegre foram objeto de publicação anterior na Revista do Instituto de Medicina Tropical de São Pau$10^{6}$. De modo geral, foram identificados níveis baixos de esporos, se considerarmos a tabela citada por Portnoy e Barnes ${ }^{7}$. Verificamos um pequeno aumento de esporos nos meses do verão.
É sobejamente conhecido que elementos presentes no ar atmosférico sofrem influência de fatores climáticos, como regime de ventos, chuvas, temperatura, grau de insolação, presença de terras devolutas, etc. e, também, de fatores associados à urbanização, como presença de prédios, poluição automotiva e industrial, entre outros. A exposição a fungos dentro de moradias depende da presença de fungos no ar atmosférico e das condições do ambiente interno como ventilação, umidade, presença de carpetes, animais e plantas.

$O$ estudo de fungos é particularmente mais difícil que a identificação de pólens devido às características intrínsecas dos esporos, conforme apontamos no artigo. A avaliação da sensibilização alérgica a fungos é dificultada pela não disponibilidade de extratos alergênicos potentes e padronizados. Este tema é objeto de excelente revisão recente de $V$. Kurup (Current Allergy and Asthma Reports 2003, 3:416-423) que julgamos oportuna e cuja leitura indicamos.

Atenciosamente

Adelina Mezzari Luiz Antonio Guerra Bernd Porto Alegre - RS
Referências

I- Mezzari A, Perin C, Santos Jr. SA, Bernd LAG, Di Gesu G. "Os fungos Anemófilos e Sensibilização em Indivíduos Atópicos em Porto Alegre, RS". Rev Assoc Med Bras 2003; 49(3): 270-273.

2- Mezzari A, Perin C, Santos Jr SS, Bernd LAG. "Idendentificação de Esporos de fungos no ar de Porto Alegre". Rev Bras Alerg Imunopatol 23 (5), 189, 2000.

3- Mezzari A, Perin C, Santos Jr. SS, Di Gesu GM, Bernd LAG "Identificação de anticorpos IgE específicos para fungos em atópicos". Rev Bras Alergia e Imunopatol 2002; 25 (5): 168. 4- Mezzari A, Perin C, Santos Jr. SS, Bernd LAG. "Características dos esporos de fungos anemófilos em Porto Alegre". Rev Bras Alergia e Imunopatol 2002; 25 (5): 169.

5- Mezzari A, Perin C, Santos Jr SS, Bernd LAG. "SURVEY OF MOLD SPORES IN PORTO ALEGRE, BRAZIL". Allergy vol 56, Suppl 68, 247-248, 2001.

6- Mezzari A, Perin C, Santos Jr. SS, Bernd LAG. "Airborne fungi in the city of Porto Alegre, Rio Grande do Sul, Brazil". Rev Inst Med Trop S Paulo 2002; 44 (5): 269.

7- Portnoy J, Barnes C. "CLINICAL RELEVANCE OF SPORE AND POLLENS COUNTS". Immunol Allergy Clin N Am 2003; 23: 389-4I0. 